\title{
Susceptibility of Norway spruce [Picea abies (L.) H. Karst.] seedlings to selected herbicides
}

\author{
Wrażliwość siewek świerka pospolitego [Picea abies (L.) H. Karst.] \\ na wybrane herbicydy
}

\author{
Tomasz Snopczyński, Aleksander Wysocki, Jerzy Sadowski
}

\begin{abstract}
Summary
Susceptibility of newly emerged seedlings of Norway spruce [Picea abies (L.) H. Karst.] to selected herbicides was examined under greenhouse conditions. The following active substances were investigated: propaquizafop ( $50 \mathrm{~g} / \mathrm{ha})$, mesotrione (100 g/ha), nicosulfuron (40 g/ha), pendimethalin (990 g/ha), fluroxypyr 125 (g/ha), clopyralid (90 g/ha), iodosulfuron-methyl-sodium (7.5 g/ha), MCPA (562.5 g/ha), clopyralid (100 g/ha) + fluroxypyr (150 g/ha) + triclopyr $(200 \mathrm{~g} / \mathrm{ha})$, bentazone $(1440 \mathrm{~g} / \mathrm{ha})$. Only after the application of propaquizafop no damages were observed. A low level of phytotoxicity (needle growth was slightly inhibited) occurred after pendimethalin and clopyralid application. The other herbicides caused major damages of seedlings. Following the visual assessment, the plants were cut and fresh shoot biomass was determined. Only propaquizafop did not affect biomass production, while the other herbicides significantly reduced the fresh biomass of seedlings.
\end{abstract}

Key words: Norway spruce; herbicides; phytotoxicity; selectivity

\section{Streszczenie}

W warunkach szklarniowych zbadano wrażliwość siewek świerka pospolitego [Picea abies (L.) H. Karst.] na wybrane herbicydy. Zastosowano następujące substancje czynne: propachizafop (50 g/ha), mezotrion (100 g/ha), nikosulfuron (40 g/ha), pendimetalinę (990 g/ha), fluroksypyr (125 g/ha), chlopyralid (90 g/ha), jodosulfuron metylosodowy (7,5 g/ha), MCPA (562,5 g/ha), chlopyralid $(100 \mathrm{~g} / \mathrm{ha})+$ fluroksypyr $(150 \mathrm{~g} / \mathrm{ha})+\operatorname{trichlopyr}(200 \mathrm{~g} / \mathrm{ha})$, bentazon $(1440 \mathrm{~g} / \mathrm{ha})$. Uszkodzeń nie zaobserwowano wyłącznie po aplikacji propachizafopu. Niski poziom fitotoksyczności (wzrost igieł został nieznacznie zahamowany) wystąpił po zastosowaniu pendimetaliny i chlopyralidu. Pozostałe herbicydy spowodowały znaczne uszkodzenia siewek. Po ocenie wizualnej, rośliny zostały ścięte i określono świeżą masę pędów. Tylko propachizafop nie wpłynął na produkcję biomasy, reszta herbicydów znacząco zredukowała świeżą biomasę siewek.

Słowa kluczowe: świerk pospolity; herbicydy; fitotoksyczność; selektywność

Instytut Uprawy Nawożenia i Gleboznawstwa - Państwowy Instytut Badawczy

Orzechowa 61, 50-540 Wrocław

t.snopczynski@iung.wroclaw.pl 


\section{Wstęp / Introduction}

Dla roślin uprawnych chwasty są silnymi konkurentami, rywalizującymi o przestrzeń do życia, wodę, światło oraz składniki mineralne. Gatunki wchodzące w skład zachwaszczenia zazwyczaj charakteryzują się: szybkim tempem wzrostu, wysoką plennością oraz dużymi zdolnościami adaptacyjnymi do zmiennych warunków środowiska. Cechy te pozwalają na szybkie zdobycie przewagi i zdominowanie cennych gospodarczo roślin, pozbawionych ochrony ze strony człowieka. Dotyczy to również drzew, dla których pierwsze lata cyklu rozwojowego są etapem, gdy konkurencja ze strony roślinności zielnej stanowi duże zagrożenie (Nilsson i wsp. 1996; Hytönen i Jylhä 2005; Łukaszewicz i Gil 2007).

Jedną z możliwości regulowania zachwaszczenia jest stosowanie herbicydów. Zabiegi herbicydowe pozwalają, przy relatywnie niskich nakładach finansowych, skutecznie ograniczać zachwaszczenie, a także, w przypadku aplikowania preparatów wolniej rozkładających się w glebie, na pewien okres zabezpieczyć plantację przed wschodami nowych chwastów. Jednak stosowanie środków chwastobójczych niesie za sobą ryzyko powstania uszkodzeń również na roślinach uprawnych. Szczególne środki ostrożności należy zachować decydując się na wykorzystanie herbicydów nieselektywnych, które trzeba aplikować bardzo precyzyjnie, w sposób zapobiegający przeniknięciu substancji czynnej do gatunku chronionego (Drogoszewski i Niziński 1993). Z uwagi na dużą mobilność niektórych herbicydów w glebie (Drogoszewski 1992) oraz możliwość znoszenia cieczy roboczej podczas oprysków (Sadowki i Kucharski 2005) metoda ta nie zawsze jest w pełni bezpieczna. Mniej ryzykowne jest stosowanie środków selektywnych, które w określonych warunkach i dawkach nie wykazują negatywnego wpływu na roślinę chronioną, a jednocześnie niszczą występujące chwasty. Zabiegi takimi preparatami mogą obejmować całą powierzchnię plantacji, co pozwala na równomierne wyeliminowanie zachwaszczenia, również w najbliższym sąsiedztwie roślin uprawnych. Tolerancja poszczególnych gatunków roślin na działanie herbicydów jest wypadkową wielu czynników. Poza wrażliwością warunkowaną genetycznie, duże znaczenie ma również budowa morfologiczna i faza rozwojowa roślin w momencie zabiegu, dawka zastosowanego preparatu oraz warunki klimatyczno-glebowe (Praczyk i Skrzypczak 2004; Soukup i wsp. 2004; Clay i wsp. 2006; Miziniak 2008; Kieloch i Rola 2010).

Celem badań było określenie wrażliwości siewek świerka pospolitego na wybrane herbicydy. W hipotezie badawczej założono, że niektóre z herbicydów wykorzystywanych na polach uprawnych mogą być selektywne dla świerka pospolitego we wczesnym okresie powschodowym.

\section{Materiały i metody / Materials and methods}

Doświadczenie przeprowadzono w warunkach szklarniowych (w temperaturze $20-24^{\circ} \mathrm{C}$ ). Oceniano działanie 10 preparatów chwastobójczych, które w trakcie prowadzenia badania były dopuszczone do stosowania na obszarze Polski w różnych grupach roślin uprawnych. Zastosowane herbicydy oraz ich dawki przedstawiono w tabeli 1 . Nasiona świerka pospolitego wysiano do doniczek wypełnionych substratem glebowym o pH około 4,8 (mieszanina piasku, uniwersalnego podłoża torfowo-mineralnego oraz torfu kwaśnego). Po wschodach wykonano przerywkę, pozostawiając w każdej doniczce 7 siewek. Badanie wykonano w układzie kompletnej randomizacji, w dwóch seriach po 3 powtórzenia. Rolę powtórzenia pełniła jedna doniczka. Oprysk herbicydami wykonano W komorze opryskowej z ruchomą dyszą (TeeJet XR 11003-VS), wydatkiem cieczy użytkowej 250 1/ha i ciśnieniem $0,2 \mathrm{MPa}$. W momencie zabiegu wszystkie siewki znajdowały się w stadium liścieni, z wykształcającymi się pierwszymi igłami. Po upływie 35 dni od zabiegu oszacowano poziom uszkodzeń, stosując 9-stopniowa skalę ( 1 - brak działania, 9 - całkowite zniszczenie roślin). Następnie rośliny ścięto i dokonano pomiaru świeżej masy części nadziemnej. Uzyskane wyniki poddano analizie wariancji, istotność różnic między średnimi oceniono testem Duncana $(\alpha=0,05)$. Wyniki z dwóch serii potraktowano jako 6 powtórzeń.

Tabela 1. Charakterystyka badanych herbicydów

Table 1. Characterization of tested herbicides

\begin{tabular}{l|c|c}
\hline \multicolumn{1}{c|}{$\begin{array}{c}\text { Nazwa handlowa } \\
\text { Trade name }\end{array}$} & $\begin{array}{c}\text { Substancja czynna } \\
\text { Active substance }\end{array}$ & $\begin{array}{c}\text { Substancja czynna, dawka g na ha } \\
\text { Active substance, rate g per ha }\end{array}$ \\
\hline Agil 100 EC & propaquizafop & 50 \\
\hline Callisto 100 SC & mesotrione & 100 \\
\hline Milagro 040 SC & nicosulfuron & 40 \\
\hline Stomp 330 EC & pendimethalin & 990 \\
\hline Starane 250 EC & fluroxypyr & 125 \\
\hline Lontrel 300 SL & clopyralid & 90 \\
\hline Huzar 05 WG & iodosulfuron-methyl-sodium & 7,5 \\
\hline Chwastox 750 SL & MCPA & 562,5 \\
\hline Fernando 225 EC & clopyralid, fluroxypyr, triclopyr & $100,150,200$ \\
\hline Basagran 480 SL & bentazone & 1440
\end{tabular}




\section{Wyniki i dyskusja / Results and discussion}

Herbicydem, który nie spowodował widocznych uszkodzeń świerka pospolitego był propachizafop (Agil 100 EC). Pozostałe substancje czynne spowodowały uszkodzenia o różnym nasileniu, w niektórych przypadkach prowadzące do całkowitego zniszczenia siewek (tab. 2). Najsilniejsze objawy fitotoksyczności odnotowano po aplikacji bentazonu (Basagran 480 SL) i mieszaniny chlopyralid + fluroksypyr + trichlopyr (Fernando 225 EC). Środki te doprowadzily do powstawania nekroz na całych siewkach. Poważne uszkodzenia pojawily się po zastosowaniu mezotrionu (Callisto $100 \mathrm{SC}$ ), który spowodował bardzo silne chlorozy i zahamowania wzrostu igieł oraz lekkie nekrozy liścieni. Po aplikacji fluroksypyru (Starane $250 \mathrm{EC}$ ), jodosulfuronu metylo-sodowego (Huzar $05 \mathrm{WG}$ ),

Tabela 2. Fitotoksyczność herbicydów dla siewek świerka pospolitego (w skali 1-9, gdzie 1 - brak uszkodzeń; 9 - śmierć rośliny) Table 2. Phytotoxicity of herbicides to Norway spruce seedlings (1-9 scale with 1 - no damage; 9 - plant death)

\begin{tabular}{|c|c|c|}
\hline $\begin{array}{l}\text { Herbicyd } \\
\text { Herbicide }\end{array}$ & $\begin{array}{l}\text { Ocena uszkodzeń (1-9) } \\
\text { Damage rating (1-9) }\end{array}$ & $\begin{array}{c}\text { Opis uszkodzenia } \\
\text { Description of damage }\end{array}$ \\
\hline Propaquizafop & 1 & brak objawów - no symptoms \\
\hline Mesotrione & $7-8$ & $\begin{array}{c}\text { bardzo silne chlorozy i zahamowania wzrostu igieł, } \\
\text { lekkie nekrozy liścieni } \\
\text { very strong chlorosis and inhibition of needle growth, } \\
\text { slight cotyledon necrosis }\end{array}$ \\
\hline Nicosulfuron & $4-5$ & $\begin{array}{l}\text { średnio nasilone zahamowanie wzrostu igieł } \\
\text { medium inhibition of needle growth }\end{array}$ \\
\hline Pendimethalin & 2 & $\begin{array}{l}\text { lekkie zahamowanie wzrostu igieł } \\
\text { slight inhibition of needle growth }\end{array}$ \\
\hline Fluroxypyr & 6 & $\begin{array}{l}\text { silne zahamowanie wzrostu igieł, silne deformacje liścieni } \\
\text { strong inhibition of needle growth, strong cotyledon deformation }\end{array}$ \\
\hline Clopyralid & $1-2$ & $\begin{array}{l}\text { bardzo lekkie zahamowanie wzrostu igieł } \\
\text { very slight inhibition of needle growth }\end{array}$ \\
\hline Iodosulfuron-methyl-sodium & 5 & $\begin{array}{l}\text { silne zahamowanie wzrostu igieł } \\
\text { strong inhibition of needle growth }\end{array}$ \\
\hline MCPA & $4-5$ & $\begin{array}{l}\text { średnio nasilone zahamowanie wzrostu igieł, } \\
\text { bardzo lekkie deformacje liścieni } \\
\text { medium inhibition of needle growth, } \\
\text { very slight cotyledon deformation }\end{array}$ \\
\hline Clopyralid + fluroxypyr + triclopyr & $8-9$ & $\begin{array}{l}\text { bardzo silne nekrozy całych siewek } \\
\text { very strong seedling necrosis }\end{array}$ \\
\hline Bentazone & $8-9$ & $\begin{array}{l}\text { bardzo silne nekrozy całych siewek } \\
\text { very strong seedling necrosis }\end{array}$ \\
\hline
\end{tabular}

Tabela 3. Produkcja biomasy przez $P$. abies pod wpływem stresu herbicydowego

Table 3. Biomass production by P. abies under the influence of herbicide stress

\begin{tabular}{l|c|c}
\hline \multicolumn{1}{c|}{$\begin{array}{c}\text { Herbicyd } \\
\text { Herbicide }\end{array}$} & $\begin{array}{c}\text { Śrieża masa } \\
\text { Fresh weight } \\
\text { [g per 1 plant }]\end{array}$ & $\begin{array}{c}\text { Redukcja świeżej masy } \\
\text { Fresh weight reduction } \\
\text { [ ] }]\end{array}$ \\
\hline Obiekt kontrolny - Control object & $0,091 \mathrm{a}$ & 0 \\
\hline Propaquizafop & $0,087 \mathrm{a}$ & 4 \\
\hline Mesotrione & $0,039 \mathrm{e}$ & 37 \\
\hline Nicosulfuron & $0,063 \mathrm{c}$ & 15 \\
\hline Pendimethalin & $0,077 \mathrm{~b}$ & 35 \\
\hline Fluroxypyr & $0,059 \mathrm{~cd}$ & 14 \\
\hline Clopyralid & $0,078 \mathrm{~b}$ & 40 \\
\hline Iodosulfuron-methyl-sodium & $0,055 \mathrm{~d}$ & 37 \\
\hline MCPA & $0,057 \mathrm{~cd}$ & 70 \\
\hline Clopyralid + fluroxypyr + triclopyr & $0,027 \mathrm{f}$ & 73 \\
\hline Bentazone & $0,025 \mathrm{f}$ & \\
\hline
\end{tabular}

Wartości oznaczone tą samą literą nie różnią się istotnie - Means followed by the same letter are not significantly different 
nikosulfuronu (Milagro 040 SC), MCPA (Chwastox 750 SL) zaobserwowano znaczne zahamowanie wzrostu igieł. Dodatkowo na obiektach traktowanych fluroksypyrem i MCPA pojawiły się deformacje liścieni. Niewielkie objawy fitotoksyczności odnotowano po opryskach pendimetaliną (Stomp 330 EC) i chlopyralidem (Lontrel $300 \mathrm{SL}$ ), były to wyłącznie nieznacznie nasilone zahamowania wzrostu igieł. Następstwem fitotoksycznego działania herbicydów były ubytki świeżej masy roślin (tab. 3). Jedynie w przypadku propachizafopu nie odnotowano statystycznie potwierdzonej redukcji biomasy. Pozostałe herbicydy spowodowały istotne obniżenie świeżej biomasy siewek w porównaniu do obiektu nieopryskiwanego.

Zachwaszczenie pojawiające się na nowo zakładanych plantacjach stanowi na ogół duże zagrożenie, gdyż rośliny uprawne we wczesnym okresie powschodowym mają niewielkie zdolności konkurencyjne i często przegrywają rywalizację o czynniki niezbędne do życia $\mathrm{z}$ wielogatunkowym zbiorowiskiem chwastów. Dotyczy to zwłaszcza gatunków o długim okresie kiełkowania i początkowo powolnym wzroście (Davies 1987; Adamczewski i wsp. 1997; Remlein-Starosta i Nijak 2007). Zabiegi herbicydowe pozwalają na efektywne eliminowanie niepożądanej roślinności występującej w tym często krytycznym okresie, jednak krótko po wschodach, tolerancja roślin na działanie środków chwastobójczych jest zazwyczaj niska i ryzyko powstania uszkodzeń na gatunku chronionym jest wówczas większe niż w późniejszych fazach rozwojowych. Dopiero wraz z postępującym wzrostem, wrażliwość na herbicydy stopniowo maleje, lecz jest to zależne zarówno od gatunku rośliny, jak i rodzaju substancji czynnej (Domaradzki i wsp. 2003; Praczyk i Skrzypczak 2004; Qasem 2011). Ważnym czynnikiem wpływającym na stopień fitotoksyczności herbicydów są wysokości aplikowanych dawek (O’Sullivan i Bouw 1998; Clay i wsp. 2006). W prezentowanym doświadczeniu ustalano je na podstawie etykiet-instrukcji przygotowanych przez producenta, decydując się $\mathrm{w}$ większości przypadków na najniższą $\mathrm{z}$ dopuszczonych dawek dla danego środka, co pozwoliło na zmniejszenie ryzyka pojawienia się uszkodzeń siewek, przy jednoczesnej gwarancji, że stosowana ilość substancji czynnej ma potwierdzone działanie chwastobójcze w warunkach glebowo-klimatycznych naszego kraju.

Pośród badanych środków, najwyższą selektywność dla siewek świerka pospolitego wykazał propachizafop, który nie wywołał dostrzegalnych uszkodzeń roślin ani statystycznie potwierdzonych ubytków świeżej biomasy roślin. Herbicyd ten, jako jedyny $\mathrm{z}$ wykorzystanych w doświadczeniu, jest dopuszczony w Polsce do selektywnego zwalczania chwastów w szkółkach i uprawach leśnych (termin ważności aktualnego zezwolenia dla preparatu zawierającego propachizafop - Agil 100 EC upływa 31.12.2013). W dużym stopniu selektywne okazały się również pendimetalina i chlopyralid, które nieznacznie zahamowały wzrost igieł, co wiązało się $\mathrm{z}$ redukcją biomasy sięgającą odpowiednio 15 i 14\%. Powyższe substancje czynne są selektywne dla licznych gatunków roślin uprawnych, co przekłada się na szerokie wykorzystywanie ich w rolnictwie (Tomlin 2006). Propachizafop, chlopyralid i pendimetalina są również $\mathrm{w}$ dużym stopniu selektywne dla wielu gatunków drzew, co stwarza możliwość stosowania ich w produkcji szkółkarskiej oraz na obszarach leśnych (Willoughby i Palmer 1997; Dixon i wsp. 2005, 2006; Willoughby i wsp. 2009). Fitotoksyczność pozostałych herbicydów wykorzystanych w doświadczeniu była wysoka, co przejawiało się znacznymi uszkodzeniami siewek oraz redukcją świeżej biomasy przekraczającą $30 \%$. W sytuacji, gdy pomimo powstałych uszkodzeń siewki nie zamierały, możliwe jest, że objawy fitotoksycznego działania herbicydów mogłyby wraz z upływem czasu stopniowo ustępować i ostatecznie nie wpłynąć negatywnie na dalszy wzrost roślin. W badaniach Sekutowskiego i wsp. (2011) uszkodzenia na ślazowcu pensylwańskim (Sida hermaphrodita Rusby) spowodowane przez większość testowanych herbicydów utrzymywały się przez okres około 21 do 56 dni od momentu aplikacji, nie wpływając negatywnie na dalszy rozwój i wzrost. Z kolei South (2000) badając toksyczność różnych dawek chlopyralidu dla trzech gatunków sosny (Pinus taeda L., P. elliottii Engelm. var. elliottii, P. palustris Mill.) zaobserwował, że pojawiające się uszkodzenia na Pinus taeda i P. elliottii były niedostrzegalne po upływie 3 miesięcy od zabiegu. Tego rodzaju długoterminowe obserwacje są zazwyczaj prowadzone w warunkach polowych, jednak doświadczenia szklarniowe pozwalają na wstępną selekcję herbicydów do dalszych badań.

\section{Wnioski / Conclusions}

1. Herbicydem w najwyższym stopniu selektywnym dla siewek świerka pospolitego był propachizafop aplikowany $\mathrm{w}$ dawce $50 \mathrm{~g} / \mathrm{ha}$. Substancja ta nie miała wpływu na powstanie uszkodzeń oraz na produkcję nadziemnej biomasy roślin.

2. W dużym stopniu selektywna okazała się pendimetalina w dawce $990 \mathrm{~g} / \mathrm{ha} \mathrm{i}$ chlopyralid w dawce $90 \mathrm{~g} / \mathrm{ha}$, które spowodowały lekkie zahamowanie wzrostu igieł, co wiązało się ze statystycznie potwierdzoną redukcją świeżej masy roślin, sięgającą odpowiednio 15 i $14 \%$.

3. Efektem działania pozostałych herbicydów, tj.: mezotrionu, nikosulfuronu, fluroksypyru, jodosulfuronu metylosodowego, MCPA, bentazonu oraz mieszaniny chlopyralid + fluroksypyr + trichlopyr były znaczne uszkodzenia oraz przekraczająca $30 \%$ redukcja biomasy siewek.

Prezentowane badania wykonano w ramach zadania 2.6 Programu Wieloletniego Instytutu Uprawy Nawożenia i Gleboznawstwa - Państwowego Instytutu Badawczego w Puławach. 


\section{Literatura / References}

Adamczewski K., Skrzypczak G., Lisowicz F., Bubniewicz P. 1997. Aktualne problemy ochrony kukurydzy w Polsce. Zesz. Probl. Post. Nauk Rol. 450: 63-78.

Clay D.V., Dixon F.L., Willoughby I. 2006. Efficacy of graminicides on grass weed species of forestry. Crop Prot. 25: $1039-1050$.

Davies R.J. 1987. Trees and Weeds. Forestry Commision Handbook No. 2. HMSO, London, 36 pp.

Dixon F.L., Clay D.V., Willoughby I. 2005. The tolerance of young trees to applications of clopyralid alone and in mixture with foliaracting herbicides. Forestry $78:$ 353-364.

Dixon F.L., Clay D.V., Willoughby I. 2006. Evaluation of the selectivity of herbicides as potential replacements for atrazine in forestry. Scott. Forestry 60 (3): 6-14.

Domaradzki K., Kieloch R., Rola H. 2003. Skuteczność herbicydów w zależności od dawki i fazy rozwojowej chwastów. [Herbicide efficacy depending on the dose and stage of development of weeds]. Prog. Plant Prot./Post. Ochr. Roślin 43 (1): 109-114.

Drogoszewski B. 1992. Skutki toksycznego działania Azoprimu 50, Roundupu i Velparu stosowanych na międzyrzędziach uprawy z dębem (Quercus sessilis Ehrh.). PTPN, Prace Kom. Nauk Rol. Leśn. 74: 39-44.

Drogoszewski B., Niziński Z. 1993. Wpływ odchwaszczania uprawy leśnej Roundupem i Velparem na przeżywalność i wzrost świerka [Picea abies (L.) Karst.]. PTPN, Prace Kom. Nauk Rol. Leśn. 76: 47-51.

Hytönen J., Jylhä P. 2005. Effects of competing vegetation and post-planting weed control on the mortality, growth and vole damages to Betula pendula planted on former agricultural land. Silva Fennica 39: 365-380.

Kieloch R., Rola H. 2010. Sensitivity of winter wheat cultivars to selected herbicides. J. Plant Prot. Res. 50 (1): 35-40.

Łukaszewicz J., Gil W. 2007. Historia i teraźniejszość zalesiania i odnawiania lasu siewem. Sylwan 151 (3): 11-22.

Miziniak W. 2008. Wpływ herbicydów na wybrane odmiany wierzby energetycznej (Salix viminalis). [Effect of herbicides on some cultivars of Salix viminalis]. Prog. Plant Prot./Post. Ochr. Roślin 48 (1): 301-306.

Nilsson U., Gemmel P., Hällgren J.-E. 1996. Competing vegetation effects on initial growth of planted Picea abies. New Zeal. J. Forest. Sci. $26(1-2): 84-98$.

O’Sullivan J., Bouw W.J. 1998. Sensitivity of processing sweet corn (Zea mays) cultivars to nicosulfuron/rimsulfuron. Can. J. Plant Sci. 78: $151-154$.

Qasem J.R. 2011. Herbicides applications: problems and considerations. p. 643-664. In: "Herbicides and Environment" (A. Kortekamp, ed.). InTech, Rijeka, 746 pp.

Praczyk T., Skrzypczak G. 2004. Herbicydy. PWRiL, Poznań, 274 ss.

Remlein-Starosta D., Nijak K. 2007. Ślazowiec pensylwański - wstępne wyniki badań nad możliwościami ochrony przed agrofagami. [Virginia mallow - first results of investigation on possibilities of pest and diseases control]. Prog. Plant Prot./Post. Ochr. Roślin 47 (4): $358-362$.

Sadowski J., Kucharski M. 2005. Skutki niewłaściwego, w tym celowego stosowania herbicydów. [Effects of improper use of herbicides including purposeful one]. Prog. Plant Prot./Post. Ochr. Roślin 45 (1): 429-434.

Sekutowski T., Rola J., Rola H. 2011. Selektywność oraz skuteczność działania herbicydów stosowanych w nasadzeniach ślazowca pensylwańskiego (Sida hermaphrodita Rusby) przeznaczonego na cele energetyczne. [Selectivity and effectiveness of herbicides applied in virginia mallow (Sida hermaphrodita Rusby) intended for energy purposes]. Prog. Plant Prot./Post. Ochr. Roślin 51 (4): $1864-1869$.

Soukup J., Jursik M., Hamouz P., Holec J., Krupka J. 2004. Influence of soil pH, rainfall, dosage, and application timing of herbicide Merlin 750 WG (isoxaflutole) on phytotoxicity level in maize (Zea mays L.). Plant Soil Environ. 50: 88-94.

South D.B. 2000. Tolerance of southern pine seedlings to clopyralid. South. J. Appl. For. 24: 51-56.

Tomlin C.D.S. (ed.). 2006. The Pesticide Manual. 14th ed. BCPC, Alton, 1350 pp.

Willoughby I., Palmer C. 1997. Weed Control in Christmas Tree Plantations. Field Book 15. HMSO, London, 41 pp.

Willoughby I., Balandier P., Bentsen N.S., McCarthy N., Claridge J. 2009. Forest Vegetation Management in Europe: Current Practice and Future Requirements. COST office, Brussels, $156 \mathrm{pp}$. 